\title{
Mujeres ante las violencias. Valoración de la información periodística sobre la violencia de género por parte de mujeres supervivientes*
}

\author{
Belén Zurbano-Berenguer** \\ Salomé Solá-Morales *** \\ Sergio Marín-Conejo ${ }^{* * * * * *}$
}

Resumen

Este artículo explora las lecturas y valoraciones que realizan mujeres víctimas/supervivientes de violencias sobre los contenidos mediáticos que abordan la violencia de género. A partir de la técnica del grupo de discusión, un grupo de mujeres con experiencias de violencias reflexionan sobre la calidad de la información, la importancia de los profesionales o las respuestas que en ellas producen los tratamientos mediáticos actuales de este problema social. Entre los resultados cabe destacar las críticas a la superficialidad y el sensacionalismo que aún hoy está presente en los medios de comunicación social.

Palabras clave: Género, Violencia de género, Feminismo, Investigación social, Medios de comunicación de masas.

\footnotetext{
* Recibido el 23 abril 2019, aceptado el 03 noviembre 2020. La dra. Zurbano-Berenguer ha sido la responsable del diseño y desarrollo de los grupos de discusión; la dra. Sola-Morales y el dr. Marín-Conejo han contribuido al tratamiento analítico de la información y a la redacción del manuscrito.

** Profesora de Periodismo y Comunicación, Universidad de Sevilla, Sevilla, España. bzurbano@us.es / http://orcid.org/0000-0002-2743-236X

*** Profesora de Periodismo y Comunicación, Universidad de Sevilla, Sevilla, España. ssolamorales@gmail.com / https://orcid.org/0000-0001-7085-4595

**** Profesor de Filología, Universidad de Sevilla, Sevilla, España smarin@us.es / https://orcid.org/0000-0002-3022-6532 
Women Facing Violence. How Women Survivors Assess News About Gender Violence

\begin{abstract}
This article explores the readings and assessments of media content about gender violence made by women who are victims / survivors of violence. Using a discussion group technique, a group of women with experiences of violence reflected on the quality of information, the importance of professionals and their own responses to current media treatments of this social problem. Among the results, it is worth highlighting criticisms of the superficiality and sensationalism still present in the social communication media.
\end{abstract}

Keywords: Gender, Gender violence, Feminism, Social investigation, Mass media. 


\section{Introducción}

En las últimas décadas ha aumentado el interés internacional por la representación de la violencia contra las mujeres en las noticias. No obstante, la mayor parte de las investigaciones se han centrado en cómo los mensajes sobre la violencia contra las mujeres se enmarcan en los relatos que elaboran los medios de comunicación (Sutherland, 2015). La escasez de estudios sobre el consumo mediático de las mujeres, y, en concreto, sobre la recepción de las violencias que sufren, inspira el interés de este artículo que profundiza en la valoración que las mujeres supervivientes hacen de las noticias sobre violencia de género. A pesar de que existe una literatura científica cada vez más amplia con relación a la recepción de género (Ganito y Ferreira, 2016), este no es el objeto de nuestro artículo, que se centra concretamente en la recepción de los mensajes sobre violencias por parte de las propias supervivientes de estas violencias (noción que amplía sobremanera las lecturas de género), y justamente este abordaje está muy inexplorado aún.

Si la matriz estudios de recepción-mujeres-violencias es un trinomio con escasa trayectoria, las investigaciones desde la perspectiva de las víctimas están aún menos desarrolladas. En gran medida esto se debe a que en la mayoría de los casos los estudios sobre violencias contra las mujeres (en adelante VVCMM) se centran en los efectos más que en las lecturas y a que éstos suelen estudiarse de forma genérica sin atender a variables como el sexo o la experiencia de violencia.

Hay un creciente interés internacional en describir la violencia contra las mujeres en las noticias y el impacto que puede tener informar sobre ello en la compresión, actitudes y comportamientos de la población. Hasta la fecha, la atención de la mayoría de las investigaciones se ha centrado en cómo los mensajes mediáticos sobre violencia contra las mujeres se enmarcan en las noticias (Sutherland et al., 2015:32, Traducción de las autorías). ${ }^{1}$

Los escasos estudios realizados focalizan sus conclusiones en las consecuencias sociales (preactivación, desensibilización, catarsis, desinhibición, legitimación...), que tienen los contenidos violentos sobre la población general y sobre las conductas agresivas (Feshbach, 1984; Bandura, 1996; Phillips, 1986; Baron y Byrne, 1994; Berkowitz, 1984; Harris, 1999; Sparks y Sparks, 2000, entre muchos otros) o en cómo la violencia afecta a la conducta masculina en particular (Anderson y Saunders, 2003; Fulu, Warner; Miedema; Jewkes; Roselli y Lang, 2013; Heilman; Hebert y PaulGera, 2014; Sanmartín; Iborra; García y Martínez, 2010).

No obstante, la obra de Schelesinger et al. (1992) aborda en un mismo estudio dos de los elementos fundamentales que no suelen abundar en la literatura sobre medios y violencia: las VVCMM como contenido mediático y la mujer como receptora de éstas. En Women Viewing Violence (1992) se aborda la interpretación que hacen las mujeres sobre contenidos específicos sobre violencias por razón de género y se explotan resultados tanto cuantitativos como cualitativos basados en la propia experiencia de recepción de mujeres tanto violentadas como no violentadas. A partir de la pregunta -¿qué hacen las mujeres con la violencia que ven en la televisión? - se profundiza en la relación entre mujeres, medios y VVCMM. El principal resultado de esta investigación evidenció que la variable más influyente es la experiencia de la violencia.

En este contexto, se hace necesario estudiar en profundidad si las representaciones de VVCMM son positivas o negativas, útiles o contraproducentes y sus consecuencias sociales, ya que los efectos sobre las políticas de comunicación y los consensos deontológicos deben estar guiados por resultados solventes y fiables. Estudios elaborados desde la teoría del framing ya han tomado el testigo y han concluido, hasta el momento, que en la transmisión de las VVCMM influye, no tanto la producción-exposición a las violencias como la forma que adquieren las representaciones, pudiendo el marco de sentido en que se insertan generar efectos contrarios (Vives-Cases, Torrubiano y Álvarez, 2009).

\footnotetext{
1 "There is growing international interest in the portrayal of violence against women in the news and the impact that reporting may have on community understanding, attitudes and behaviours. To date, most research attention has focused on how media messages about violence against women are framed in the news" (Sutherland et al., 2015:32).
} 
Las mujeres como verdaderas protagonistas de la violencia

Mientras que el feminismo se ha ocupado de teorizar sobre el concepto de violencia/s, sus manifestaciones y su traslación como objeto simbólico (contenidos, representaciones y tratamientos en los media), los estudios en comunicación han ocupado sus esfuerzos en estudiar los efectos de la violencia representada en la sociedad. Ambos enfoques han trabajado, generalmente, a partir del análisis de contenido. Sin embargo, y asumiendo los presupuestos feministas, es necesario preguntarse, no sólo cómo son emitidos los contenidos sobre violencias de género sino cómo son recibidos y qué papel puede jugar el género en estas lecturas.

Los trabajos sobre violencia y medios apenas han indagado en la especificidad de la violencia de género mientras que los estudios de género suelen disolver el fenómeno de la violencia en la más amplia variable de la dominación masculina. Los investigadores interesados en la violencia y los medios han sido especialmente sensibles al estudio de los efectos que los contenidos de los medios ejercían sobre el público, aunque sin diferenciar de forma muy precisa entre las formas de violencia que representaban esos medios (Soriano, J., 2004:155).

Algunos estudios clásicos ya se han preocupado sobre la mayor aceptación de determinados programas, formatos y contenidos en mujeres (Radway, 1991; Barbero, 1987, 1988, 1992), aduciendo su aplicabilidad al contexto vital de las receptoras y a su socialización e, incluso, criticando la inquebrantable frontera entre la Cultura en mayúsculas y los consumos populares. Se hace necesario en este punto reivindicar, pues, el acercamiento a los estudios de recepción desde el concepto de cultura popular sin ningún otro afán que demandar la misma máxima que la historiografía: la legitimación de los sujetos actores y actrices de su propia historia, y de la Historia, con mayúsculas. La recepción de las mujeres no debe ser un producto exótico ni un accesorio, sino que ha de comprenderse como una lectura necesaria, propia, contextual y legítima de contenidos que les afectan desde una doble perspectiva, como usuarias de los medios y receptoras, y también como protagonistas de los contenidos, es decir, como mujeres violentadas.

A este respecto, el género ha de ser contemplado en los estudios de recepción desde una doble perspectiva: identitaria (la mujer como sujeto de opresión patriarcal, como víctima potencial) y privilegiada (la categoría "privilegio epistémico del oprimido" funciona con una fuerza especial en este contexto constituyendo el privilegio la experiencia de la violencia). En la interseccionalidad entre la recepción femenina y los contenidos sobre VVCMM es especialmente interesante hacer notar esta dualidad que les confiere una fuerza interpretativa resignificada: las mujeres son las receptoras de una información, pero no de cualquier información, son lectoras (en un sentido amplio) de los relatos sobre sus propias violencias, ya que comparten si no la experiencia de la violencia, la plena conciencia colectiva de su situación de víctimas potenciales. De hecho, en mujeres que no han sufrido violaciones se encuentra una sensación de miedo y alerta constante ante una agresión sexual asimilable a haber sufrido propiamente una agresión (De Miguel, 2005)

Haciendo propias las palabras de Soriano (2004), este artículo ha apostado por superar el plano del análisis de los contenidos informativos y ha optado por comprender las relaciones que se establecen entre estos contenidos y las mujeres para "describir el impacto de la violencia [televisada] sobre las mujeres en la concepción sobre ellas, sobre sus identidades de género" (Miller, 1994). En este sentido el horizonte que subyace a este estudio es hacer valer las voces de las mujeres y permitir hablar a las subalternas.

\section{Metodología}

Para ello, se ha llevado a cabo una metodología cualitativa ya que los objetivos planteados, y que exponemos a continuación, no son de carácter demostrativo sino argumentativo. Hemos puesto el acento en los relatos de un grupo de discusión, y se ha trabajado con estos como un material básico para explorar las valoraciones subjetivas que las mujeres violentadas tienen sobre los contenidos de VVCMM. Los objetivos de esta investigación son tres consisten en cuestionar si existe una percepción de un cambio a partir de la promulgación de la Ley 1/2004 por parte de las mujeres violentadas; analizar las valoraciones que las mujeres supervivientes tienen sobre la actividad 
periodística acerca de la VVCMM y, por último, dar a conocer las reflexiones éticas actuales sobre el deber ser de la información periodística que sostienen las propias víctimas.

Con esta perspectiva, son de gran relevancia los elementos biográficos y narrativos que las informantes presentan sobre sus relaciones con la información sobre la violencia en sus diferentes formas, ya sean de carácter psíquico (sentimientos, emociones, creencias y percepciones) o de carácter social (normas, valores, usos y hábitos). Estos datos sirven para entender las lecturas que las mujeres hacen de la VVCMM. Más aún cuando aquello que interesa dilucidar es el modo en el que las supervivientes valoran, leen y se identifican con los contenidos mediáticos violentos. Las preguntas de investigación que han guiado este estudio han sido tres: La primera, les cuestionaba sobre su valoración, como supervivientes, sobre la actividad periodística que informa de la VVCMM; la segunda pregunta se dirigía a su percepción de algún cambio desde la promulgación de la Ley 1/2004; y la tercera, se dirigía a sus reflexiones éticas que, como mujeres víctimas y supervivientes de violencias, tienen sobre el deber ser de la información periodística.

Es necesario precisar que el análisis de estos relatos como receptoras, o el análisis descriptivo, sólo tiene utilidad en la medida en que nos acerca a las razones y los motivos. Es decir, nos permite comprender mejor de qué modo y por qué las mujeres realizan determinadas valoraciones sobre los relatos, personajes o imágenes en los medios sobre la VVCMM.

\section{Muestra}

Se ha realizado un muestreo teórico por el carácter exploratorio. Esta estrategia metodológica se basa en las aportaciones clásicas de Barney G. Glaser y Anselm L. Strauss (1967) y que, debatidas fueron desarrolladas posteriormente (Glaser, 1978, 1992, 1995; Strauss y Corbin, 1990). Desde la perspectiva de la teoría fundamentada un muestreo teórico, las conclusiones no son de tipo estadístico, por lo que no pretende ni es representativo de ninguna población. Sin embargo, sí puede dar una explicación o dar significado. En este sentido, la compilación de relatos y extracción de datos configura, poco a poco, el tamaño de la muestra (Glaser, 1992; Coyle, 1997). Además, hay que tener en consideración que las conclusiones obtenidas en este tipo de trabajo cualitativo, exploratorio y descriptivo son muestras teóricas intencionadas, por lo que no pueden ni deben ser generalizadas. Se trata de la percepción de un grupo, en un lugar y en un momento dado por lo que sólo son válidas en relación únicamente con las personas que participaron. Sin embargo, tendrán validez externa porque pueden aportar conocimiento para comprender un fenómeno o proceso, $y$ así, poder profundizar en él. Este estudio se enmarca más en la búsqueda de la comprensión del proceso de recepción que realizan las mujeres violentadas respecto a la VVCMM más que en la obtención de conclusiones definitivas o respuestas axiomáticas. No obstante, los resultados creado con las participantes cobran gran valor por el aporte testimonial que las mujeres hacen desde su experiencia. Y, sobre todo, porque sirven para asentar las bases e hipótesis sobre las que seguir trabajando con los discursos de mujeres violentadas en el futuro.

El grupo de discusión estuvo participado por ocho mujeres, de entre los 30 y los 50 años, con un nivel de estudios medio-bajo (estudios primarios o secundarios), residentes en Andalucía en entornos rurales (en poblaciones de entre 8.000 y 10.000 habitantes), con una media de 1,75 hijos (todas ellas tenían entre uno y cuatro descendientes), la mitad de ellas desempleadas y la otra mitad ocupadas.

Para la descripción de las participantes, velando siempre por salvaguardar su anonimato, se ha realizado una codificación del perfil de las mujeres a partir de una numeración ordinal. Por esta misma razón, los datos sociodemográficos aportados, aunque mínimos, también han sido transformados a cuotas o segmentos estratificados (rangos) con el objetivo de diluir la información concreta que pudiera ayudar a la identificación individual de las participantes. 
Figura 1. Perfil sociodemográfico de las integrantes del grupo de discusión

\begin{tabular}{|l|c|c|l|l|}
\hline Participante & Edad & Número hijos/as & Situación laboral & $\begin{array}{l}\text { Nivel de } \\
\text { estudios }\end{array}$ \\
\hline P1_G1_11_12 & $40-49$ & 2 & Desempleada & Secundarios \\
\hline P2_G1_11_12 & $30-39$ & 2 & Desempleada & Primarios \\
\hline P3_G1_11_12 & $30-39$ & 3 & Desempleada & Secundarios \\
\hline P4_G1_11_12 & $30-39$ & 1 & Empleada & Primarios \\
\hline P5_G1_11_12 & $40-49$ & 1 & Desempleada & Secundarios \\
\hline P6_G1_11_12 & $30-39$ & 1 & Empleada & Primarios \\
\hline P7_G1_11_12 & --- & 1 & Empleada & Secundarios \\
\hline P8_G1_11_12 & $40-49$ & 2 & Empleada & Primarios \\
\hline
\end{tabular}

Elaboración propia.

Las integrantes del grupo presentan como características homogéneas la experiencia de violencia sufrida, la terapia psicológica de superación que siguen, la condición de madres y su pertenencia a un ámbito geográfico de tipo rural. Frente a estas características, hay ciertos elementos de heterogeneidad como la diferencia de edad (sin ser excesiva y, por tanto, excluyente para una composición eficiente del grupo), la situación laboral y el tipo de violencias sufridas.

Cabe destacar que, por la edad de las componentes de la muestra estudiada, estas son usuarias de medios solventes dentro del periodo analizado (2000-2012). Con ello, no eran ni adolescentes ni jóvenes. La razón principal es que pueden presentar patrones de consumo mediático diferentes a otros segmentos y alejados en general del soporte impreso. Por esta misma razón, el grupo de muestra tampoco estaba compuesto por mujeres excesivamente maduras ya que podrían acusar algún distanciamiento forzoso de la prensa.

A la hora de seleccionar a las informantes, las categorías de referencia citadas han sido los criterios prioritarios. Para localizarlas, se ha optado por elegir personas que reuniesen los criterios de representatividad, pertenencia y predisposición positiva. Para ello, hemos recurrido a la práctica antropológica de búsqueda por terceros y asociaciones. En este caso, se ha recurrido a un servicio público de atención psicológica radicado en la comunidad andaluza para la superación de la violencia como intermediario entre las participantes y las investigadoras ${ }^{3}$. Las dificultades presentadas en la búsqueda y selección de las informantes han sido fácilmente subsanadas y hemos podido contar con 8 participantes ${ }^{4}$.

El modelo de grupo de discusión diseñado

El cuestionario-guía del grupo de discusión que se ha utilizado se inspira fundamentalmente en la siguiente estructura:

\footnotetext{
2 En España los estudios primarios son aquellos obligatorios que se cursan entre los 6 y los 12 años en el sistema público de forma gratuita y obligatoria. La educación secundaria se corresponde con la denominada "Educación Secundaria Obligatoria (ESO)" y comprende cuatro cursos, entre los 12 y los 16 años.

3 No se ofrecen más datos sobre el mismo para garantizar la intimidad y seguridad de las participantes.

${ }^{4}$ Ninguna de las autoras de este trabajo tiene relación con dicho servicio. La investigación desarrollada no presenta conflicto de intereses. Además, se cumplieron todos los compromisos éticos respecto al tratamiento de los datos sensibles con los que se trabaja.
} 


\begin{tabular}{|c|c|c|}
\hline & OBJETIVO & ÁREAS DE INTERÉS \\
\hline Objetivo 1 & $\begin{array}{l}\text { Conocer las valoraciones sobre la } \\
\text { actividad periodística }\end{array}$ & $\begin{array}{l}\text { Reconocimiento de la labor periodística como } \\
\text { positiva o negativa } \\
\text { Valoración sobre la formación específica y el } \\
\text { saber hacer de los periodistas } \\
\text { El interés de la prensa en las VVCMM como } \\
\text { problema o como suceso }\end{array}$ \\
\hline Objetivo 2 & $\begin{array}{l}\text { Conocer si existe percepción en el } \\
\text { cambio de tratamiento informativo }\end{array}$ & $\begin{array}{l}\text { Percepción de cambio a partir de la Ley } \\
1 / 2004\end{array}$ \\
\hline Objetivo 3 & $\begin{array}{l}\text { Conocer las reflexiones éticas desde el } \\
\text { triple rol de usuarias, protagonistas del } \\
\text { discurso mediático de las VVCMM y } \\
\text { madres }\end{array}$ & $\begin{array}{l}\text { Valoración sobre el uso de las fotografías de } \\
\text { prensa } \\
\text { Reflexiones sobre el tratamiento } \\
\text { debido/deseado: evaluación ética del } \\
\text { decálogo del diario Público } \\
\text { Reflexiones sobre la necesidad y utilidad de } \\
\text { las VCCMM como tema informativo } \\
\text { Aproximación al análisis ético de una noticia }\end{array}$ \\
\hline
\end{tabular}

Estos son los tópicos que hemos trabajado: usos y consumos mediáticos; valoración de la actividad periodística; propuestas de mejoras en la comunicación periodística de la violencia y maternidades, educación, medios y violencias.

El desarrollo del grupo tuvo lugar en el espacio físico habitual de la terapia y tuvo una duración de tres horas aproximadamente. La sesión se realizó en dos bloques de una hora y media, un breve descanso con refrigerio y una hora final. Estuvo dirigido por una dinamizadora de grupos experta perteneciente al ámbito de la sanidad pública ya que las autoras del trabajo, profesoras de comunicación y periodistas, no especialistas en grupos de personas, preferíamos no interferir en el desarrollo de la técnica. Para el grupo se diseñó tanto un guión de "áreas de interés" (ver figura más arriba) como dos noticias de prensa impresa con el fin de provocar reacciones y valoraciones ante hechos concretos.

\section{Análisis de los resultados}

El análisis se ha articulado siguiendo los objetivos marcados: las valoraciones sobre la actividad periodística, la percepción (o no) de un cambio a partir de la promulgación de la Ley 1/2004 y las reflexiones éticas sobre la actualidad y deber ser de la información periodística sobre VVCMM.

En este estudio se ha combinado el análisis de contenido y el método de ejemplificación (Pujadas, 1992). Con el primero, se ha valorado la relevancia significativa que las participantes dan a ciertas categorías temáticas (tópicos) en relación con el contexto comunicativo en el que se encuentran. Esto, a su vez, se ha aplicado al discurso oral del grupo de discusión, favoreciendo de esta manera la comprensión y posterior interpretación del discurso. Con el segundo -el método de ejemplificación-, se ha reconstruido e interpretado el mundo social referencial expresado por las participantes y sus formas valorar las informaciones sobre VVCMM.

El análisis del grupo de discusión realizado planteó interesantes similitudes y diferencias en la manera de construir las valoraciones sobre la VVCMM por parte de las mujeres supervivientes que se desarrollan a continuación. 
Valoraciones de mujeres supervivientes sobre la actividad periodística acerca de la VVCMM

Los discursos derivados del análisis del grupo de discusión realizado se han centrado en cuatro elementos esenciales: la valoración de las VVCMM como tema informativo muy relevante; la identificación de la contradicción entre la responsabilidad social de los medios y sus necesidades empresariales; la constatación y crítica de la falta de formación por parte de los periodistas y profesionales que tratan el problema de las VVCMM; y la demanda de un posicionamiento moral expreso de condena por parte de éstos cuando traten el problema.

En primer lugar, las participantes valoran positivamente que las violencias de género sean un tema informativo. Que se informe sobre ello de manera habitual es considerado oportuno y necesario. Las participantes confían en un grado alto tanto en la capacidad de impacto informativo de los medios (la ciudadanía va a tener un conocimiento mayor sobre las violencias a través de ellos) como en su capacidad de cambio efectivo. Por ejemplo, muestran confianza en que a partir de la difusión de informaciones sobre el tema o de denuncias de injusticias, los medios puedan influir en una toma de decisiones más allá de plano informativo. Esta valoración sobre la oportunidad y la utilidad del tratamiento en los medios, la expresan con afirmaciones del tipo: "lo tendrían que poner más grande todavía", "ayudaría a hacer las cosas de otra manera", "es bueno que se sepa, que ellos denuncien, que salga este problema", "tienen que informar para que todo el mundo se conciencie de estas cosas".

La confianza que demuestran es dual: por un lado, confían en la labor de los medios, porque tienen una capacidad importante de llegar a la sociedad, de ampliar el impacto de los acontecimientos que narran $\mathrm{y}$, por otro, confían en que puedan cambiar la percepción sobre su experiencia vital a cuanta más gente mejor. Lo expresan del siguiente modo: "es lo que lee todo el mundo", "lo que ellos pongan llega a mucha gente", "yo puedo ayudar a una amiga (...) los medios pueden transmitir eso a todas las personas".

Por otro lado, les otorgan la capacidad de transformar con sus acciones la "conciencia social". Las participantes dejan entrever que sitúan a los medios (en aproximaciones cercanas a las teorías liberales de los medios en las que éstos son considerados los guardianes de la democracia) como mediadores ante las instituciones y dada su situación de desamparo e injusticia: "que lo que pongan para llegar a las personas que tengan que llegar y tengan manos para que esto pare. Porque no [es] sólo informar por informar como una noticia más, sino que algo llegue, que conciencie, que sirva para poner medios y no siga pasando". "Ellos llegan a todo el mundo y eso es muy importante...Son los que pueden hacer algo, ¿no? Tanto en el tironcito de oreja a la justicia también". Esta interpretación de los medios como posibles aliados parece fruto de un desconocimiento de las reglas profesionales del periodismo y de una excesiva confianza en la capacidad de influencia de los medios, pero, sobre todo, es sintomática de la necesidad de ser escuchadas, valoradas y dignificadas ante la sociedad. La demanda del papel de aliados que reclaman a los medios (situando el tema como información actual, otorgándole importancia, reivindicando incluso una condena moral por parte del periodista que elabora la noticia) responde, además, al desamparo en el que se encuentran ante la sociedad y ante el sistema jurídico. Se sienten desvalidas, sistemáticamente ignoradas $y$, aún peor, sin capacidad de cambiar su circunstancia.

En los discursos y en los gestos, en cómo se distorsionan las conversaciones volviendo siempre al aislamiento social, a la falta de soluciones, a la burocracia judicial que se ha olvidado de ellas, se infiere la desesperación de estas mujeres que, por un lado, están animadas socialmente a denunciar y a reconocerse como víctimas mientras que, por otro, no encuentran las ayudas y asideros prometidos. En este marco vital los medios de comunicación se tornan, para ellas, herramientas válidas para reivindicar ayuda, atención y dignidad.

En segundo lugar, es destacable la identificación que las participantes hacen de la contradicción entre la responsabilidad social y el carácter empresarial de la actividad informativa. A las mujeres no se les escapa que determinados tratamientos, determinadas actuaciones periodísticas son efecto de la necesidad de rentabilidad de los medios. Con respecto a qué violencias tienen cabida en la información periodística sobre violencia de género y en las reflexiones acerca de que, fundamentalmente, son los asesinatos los que ocupan las páginas de los periódicos, una de las 
participantes afirma que "parece que hay que llegar a eso para que venda más". La crítica es sostenida. Ninguna quiere ser tajante pues todas al principio se inhiben un poco (incluso algunas se retraen en sus juicios: "no compro todos los días el periódico") y utilizan condicionales y dubitaciones para expresar una creencia que comparten todas y con gran determinación: los medios, como otros estamentos sociales, cuidan de sus intereses por encima de los suyos como víctimas.

En tercer lugar, constatan la falta de formación específica y sensibilidad en los profesionales que tratan estos temas y que ha sido ya evidenciado anteriormente en trabajos como los de Zurbano (2015). Las participantes, que ante todo valoran necesaria y positiva la presencia del problema como tema informativo, son tajantes a la hora de enjuiciar el trabajo periodístico en términos de falta de empatía, de conocimiento y de sensibilidad que a veces manifiestan los periodistas cuando realizan las noticias sobre el tema: "Hablan mucho sin saber lo que se siente y lo que se pasa cuando se es víctima de violencia de género". A su entender, los profesionales a veces no saben cómo proceder: "se anticipan muchas veces, no se informan bien, no preguntan a quién deben preguntar".

Entre las valoraciones de la actividad periodística y las reflexiones éticas existe, como en este caso, una línea tan delgada y a veces son tan coincidentes que cuesta separar qué es puramente valoración sobre la actividad periodística general y qué una reflexión ética sobre prácticas concretas (que, apriorísticamente se habían marcado como dos objetivos diferenciados en este trabajo). Las participantes reivindican un tratamiento específico, adecuado y ad hoc para cada situación, pues ningún caso es igual a otro, lo que entronca con la demanda de formación y especialización que subyace a sus críticas.

$\mathrm{Su}$ rol como madres en este caso las reviste de una especial preocupación y es fundamental ya que se muestran preocupadas por los efectos en los menores cuando se acercan a las noticias desde este prisma superficial y poco empático. Inmersas en la lucha personal que ellas ya han iniciado frente a la violencia se muestran necesitadas de aliados en esta batalla tan desigual y así ven a los medios, juzgando con dureza todo lo que sirva a intereses diferentes. Una de las mujeres participantes reclama "que tengan un poquito de tacto porque un niño de dos años no va a coger un periódico para leer una noticia así, pero un crío de 14, 15 años lo puede leer... Yo entiendo que tienen que informar, pero con un poquito de tacto, porque lo puede leer cualquier persona".

En este sentido, parece oportuno reconocer como acertada la decisión de utilizar el criterio de la maternidad como relevante para la conformación del grupo. Las participantes reflejan esta preocupación por los menores (que presumiblemente otro perfil de mujer con experiencia de violencia, pero sin ser madre no expresaría) de una manera absolutamente espontánea. En mitad de una reflexión alguna propone el problema de los menores como receptores potenciales como una muestra más de la poca adecuación de los formatos y tratamientos y el resto se muestran de acuerdo.

En cuarto lugar, las participantes demandan un posicionamiento explícito de tipo moral, una condena, por parte de los periodistas. Las mujeres estiman necesario que la posición de rechazo de los profesionales se haga patente a la hora de redactar las informaciones como acicate para promocionar el cambio en toda la sociedad. Desde el alto potencial de cambio que les otorgan a los medios, con esta reivindicación, parecen querer reforzar, asegurar, ese impacto en el cambio. Ajenas a las vicisitudes de la profesión y al paradigma de la objetividad como máxima informativa, tan presente aún en parte del periodismo español, las participantes reclaman que se tome partido, que se dé a conocer y que se reconozca su realidad a través de la condena de estos profesionales. Parecen buscar en ellos a los portavoces que necesitan para que se difunda el rechazo social a sus experiencias sufridas, que no siempre encuentran en sus entornos.

Percepciones sobre los posibles cambios a partir de la promulgación de la Ley 1/2004

Con respecto al segundo objetivo, relacionado con la percepción o no de un cambio a partir de la Ley 1/2004, se encuentra cierto grado aparente de disparidad que finalmente parece no ser tal. En concreto, se trabaja sobre la hipótesis de Zurbano (2015) quien sostiene que la promulgación 
de la L.O. ha supuesto un revulsivo informativo que ha propiciado un cambio de paradigma en el contexto informativo.

Una de las participantes afirma que no percibe cambio alguno. Sin embargo, enseguida otras compañeras la corrigen: sí hay cambio, cierto cambio, en que hay más noticias, "más información", pero no mejor. Otra matiza: "cada vez peor, y siempre pasará, cada vez peor". En este sentido cabe destacar que las voces expresan lo razonado, pero también lo sentido, el silencio y la soledad en la que encuentran que ni los medios de comunicación son sus aliados. De ahí que la conversación se desplace enseguida al tema de la justicia, del aislamiento de las víctimas a las que "no se echa cuenta" y que, aunque denuncien "no vale para nada". Es tremendamente costoso centrar los discursos de las mujeres sobre el ámbito informativo cuando por su experiencia vital están afectadas por muchas estructuras sociales más allá de la mediática y que, en ocasiones, les han afectado de manera más directa y grave. Las digresiones con respecto a la inutilidad de denunciar y la falibilidad de la justicia son recurrentes en el grupo. Dificultan la concreción temática y la focalización estricta en los objetivos del grupo, pero enriquecen la comprensión global de sus experiencias.

El consenso, no obstante, parece quedar claro: detectan cierto cambio, pero en un plano cuantitativo, no así en la calidad de las informaciones. Este bloque de reflexiones resulta especialmente interesante en las lecturas cualitativas que las mujeres realizan sobre el sistema social. La desazón interiorizada por las mismas ante experiencias vitales que las han superado y en las que se han sentido completamente solas que esta área de interés planteado por las investigadoras más que para hallar conclusiones mediáticas sirve para fagocitar su indignación. Un análisis minucioso de los discursos permite afirmar que existe un consenso entre ellas acerca de que hay poco cambio, pero "que algo hay".

\section{Reflexiones éticas sobre la actualidad y deber ser de la información periodística sobre VVCMM}

Sobre las reflexiones éticas que se plantean en los discursos de las participantes, se ha procedido a ordenar la información en tres bloques semánticos: en primer lugar, conocer cómo caracterizan ellas el tratamiento noticioso actual (y cómo lo valoran: positivo o negativo); saber las propuestas que hacen de cambio y, también, las disensiones que los analistas han inferido.

De forma transversal a los discursos hay que hacer notar dos elementos clave: la afectación que sienten al hablar y valorar estas noticias y la impresión general que subyace a los discursos de que el periodista no está lo suficientemente formado. La afectación especial les lleva incluso a distanciarse de estas informaciones: "intento no verlo porque me afecta personalmente". Aquí se hace patente la diferencia entre la sociedad y ellas como grupo significado poniendo de relieve además las graves secuelas de las violencias sufridas que se actualizan en cada noticia que leen, ven $\mathrm{u}$ oyen. Este es un dato significativo ya que la valoración que se hace del tratamiento noticioso es que no les parece del todo adecuado. Por un lado, las mujeres son conscientes de que es fundamental que se trate su problema en los medios para que todo el mundo conozca y para que "cambie la situación". La pregunta que cabe hacerse es, ¿̇i las noticias fueran otras, estuvieran diseñadas de otro modo, generarían la misma reacción? ¿Es rechazo a enfrentarse con su problema en una dimensión pública, a reconocerse en otras, o es un problema de enfoques, de tratamientos, de testimonios y de sensacionalismo?

El desarrollo del grupo parece discurrir hacia la segunda de las opciones: si los tratamientos fueran otros (con menos estereotipos, con más conocimientos, con más sensibilidad, con más dignidad en la presentación de las mujeres violentadas) ellas no se sentirían disociadas de los discursos ("no se nos echa cuenta"). Desde las valoraciones éticas que hacen sobre las representaciones actuales de las VVCMM se puede afirmar que no sienten que sean las mejoras lo que les lleva a identificar ciertas desviaciones de lo que creen que debe de ser un buen tratamiento $e$, incluso, hacer propuestas sobre hacia donde deben operar los cambios.

El segundo de los elementos transversales es la formación de los profesionales. Subyace la idea de que los periodistas no tienen el suficiente conocimiento como para afrontar la cobertura de este tipo de acontecimientos. Esta valoración se ve claramente en dos cuestiones: los estereotipos de los que están plagadas las noticias y (en conexión con lo anterior) la aparente búsqueda de una razón por parte de los redactores. 
Los discursos que se generan entre las mujeres rechazan estas prácticas (centrarse en minorías, buscar una razón a la violencia, a lo ocurrido, "cebarse en la familia, la droga"). Mientras que con respecto a ciertas actuaciones la explicación que ellas dan se encuentra en las necesidades de venta de los diarios o en su configuración como empresas, parece existir cierta idea de que las noticias sobre VVCMM se hacen "como una noticia más, una noticia cualquiera". Argumento que se refuerza por lo siguiente: frente a las desviaciones o incorrecciones que ellas explican a partir de dimensiones no ofrecen alternativas, pues intuyen que no pueden cambiarse las lógicas soterradas que llevan a tales comportamientos, pero frente a las desviaciones de lo que consideran ético y que sí está en mano de personas concretas (los periodistas) cambiar, sí que plantean opciones y alternativas de enfoque.

Las reflexiones éticas que las participantes hacen de la práctica comunicativa se centran sobre todo en que los medios son:

Agresivos en su tratamiento de las VVCMM. Una de las participantes afirmaba al valorar en general la conducta mediática: "Yo pienso que muchas veces [la información es] muy agresiva cuando sobre todo cuando escuchas la víctima número tal y no dicen el nombre hasta última hora, o no se conoce por lo que ha podido pasar esa persona... muy agresivo, muy superficial... muy de pasada".

Fríos y rutinarios: tratan la información como cualquier otra información. Las mujeres expresan su desacuerdo con esta frialdad: "Yo lo que creo que es eso que sí, que lo dicen como una noticia que llena una página de un periódico, algo más, un número más".

Son superficiales, no narran las situaciones reales porque no las comprenden/conocen. Para ellas existe una simplificación mediática de las violencias dado que esta es mucho más que la manifestación física - la única que en la que se centran los medios. "Debería de hablarse del tema sin llegar a la muerte", "violencia no es sólo pegar".

Los relatos son sensacionalistas y redundan en estereotipos tales como el estrato sociocultural, la delincuencia o la droga. Esto lo expresan mediante afirmaciones del tipo: "se ceban con la familia, la droga, la delincuencia", "se centran en unas minorías", "buscarle por qué a algo que no tiene por qué". Otra participante afirma: "se pasan mucho, mucho, meten el dedo en la llaga, contando las cosas".

Culpabilizan (implícitamente) a las mujeres: "la sensación que me da es que la culpa la tiene la víctima, que si lo conoció a esta edad, que si no se qué" (anexo 5:7). Que los patrones narrativos de las noticias sobre VVCMM exoneran a los agresores de responsabilidad ya ha sido puesto de manifiesto en investigaciones anteriores (Alat, 2006: 303) y aquí queda patente el efecto que estas estrategias discursivas tienen en las víctimas.

Las propuestas de cambio y mejora de la actividad informativa están en línea con lo anterior y se articulan todas bajo el paraguas común de la vocación de servicio público y el trabajo por la concienciación social. A partir de esta función principal del discurso mediático, específicamente, las mujeres demandan:

Más información sobre el problema antes de abordarlo y mayor sensibilidad ("tacto" lo llaman las participantes) a la hora de tratar estos temas: "Que tengan un poquito de tacto porque un niño de dos años no va a coger un periódico para leer una noticia así, pero un crío de 14, 15 años lo puede leer... Yo entiendo que tienen que informar, pero con un poquito de tacto, porque lo puede leer cualquier persona". Asimismo, se puede encuadrar aquí la reivindicación de dignificación de la víctima y de complejidad que subyace a discursos en la línea de "no hay que buscar el por qué, no hay que buscar una razón que no la hay". 
Mayor relevancia como tema informativo. Los discursos son difusos en cuanto a esta cuestión pues las participantes se refieren en todo momento a dimensiones ("lo tendrían que poner con letras más grandes todavía") cuando realmente, del contexto se infiere que están hablando de importancia (situación en la página, presencia de fotografías, calidad de los testimonios que alberga la noticia, etc.) y no solo de espacio, de tamaño: "Se le debería dar más importancia como yo que sé... una noticia de política o de cualquier cosa, como una noticia más vamos, no con la importancia que debería... de tener".

Dar cabida a la multiplicidad de violencias existentes y que quedan silenciadas en un discurso mediático que fundamentalmente aborda la violencia física y en su versión más brutal: "Sale cuando hay muerte nada más". Uno de los testimonios con respecto a la importancia de integrar otras violencias en los discursos es especialmente emotivo y materializa la oportunidad y pertinencia de los roles que estas mujeres sostienen dentro del grupo (violentadas, usuarias de medios, ciudadanas, madres): "A veces te puedes sentir muerta, aun estando en vida. Porque hay violencias que no te dejan vivir. Te quita hasta las ganas de respirar. O sentirte que te estás muriendo y dices: Dios mío venga ya" (habla en voz baja entre lágrimas).

Las propuestas de enfoque y representación que expresan son coherentes con respecto a las valoraciones que hacen sobre los tratamientos ético-deontológicos actuales, sin embargo, algunas reflexiones se distancian un tanto de los consensos generales sobre la cuestión, como es el caso de las fotografías. La presencia de imágenes de las víctimas se aleja claramente de las recomendaciones de preservar su anonimato. Hay otro elemento, en línea con lo anterior, que sorprende por aparentemente disonante: la identificación; el hecho de que las participantes enfrenten como negativo el no ofrecer el nombre de la víctima de una agresión: "no dicen el nombre hasta última hora". La preservación del anonimato de la víctima es uno de los elementos clave en los protocolos informativos existentes en el periodismo, pero también en otros (la información policial, por ejemplo). Sin embargo, las participantes, parecen rechazar de algún modo la falta de atención que se presta a la figura de la mujer concreta y reivindican su aparición como centro informativo (criticando que su nombre se desplace al último lugar en la noticia). Además, no rechazan el que aparezcan imágenes y la mujer sea fácilmente identificable, sino que reivindican la dignidad de las fotografías: "Es más bonito poner una foto de ella cuando estaba riendo que cuando no lo está".

Estas consideraciones y los discursos sostenidos se han entendido desde la situación personal de las víctimas las cuales se encuentran estigmatizadas. Es decir, desde la asunción de que se encuentran en un estadio vital ( $y$ en una circunstancia concreta, participando en un grupo por su condición "de") en el que se reconocen a sí mismas como "víctimas".

Desde ese rol de representantes de mujeres violentadas se erigen, por un lado, como portavoces de la dignidad de las mujeres silenciadas, ninguneadas e ignoradas por el sistema judicial (que padecen) y la sociedad (en la que viven); por otro, actúan como mujeres con una experiencia de violencia a sus espaldas y con hijos e hijas a su cargo que, ante todo, quieren que su historia, no vuelva a repetirse.

\section{Conclusiones y retos de futuro}

El presente estudio aportó resultados significativos sobre la recepción de informaciones sobre las VVCMM por parte de las mujeres supervivientes que participaron en el grupo de discusión realizado. Además, este trabajo coincide con las evidencias actuales de la literatura sobre violencias, género y medios:

La evidencia empírica de los estudios que buscan entender el contenido de los mensajes mediáticos ha demostrado de forma consistente las discrepancias entre las realidades de las experiencias de mujeres que han sufrido violencias y la "realidad" descrita en los medios, 
sugiriendo que no ha llegado a producirse un cambio positivo considerable (Shuterland et al., 2015:14, traducción de las autorías). ${ }^{5}$

En relación con la primera pregunta de investigación sobre qué valoración tienen las mujeres sobre la actividad periodística se pudo concluir que la VVCMM es un tema informativo muy relevante que no puede ser obviado ni silenciado en la agenda mediática. Ahora bien, las mujeres participantes constataron que existe una contradicción entre la responsabilidad de los medios y sus necesidades empresariales que, no obstante, se podrían atenuar si existiese una formación específica para los periodistas y profesionales que tratan el tema de la VVCMM. A su vez, las participantes demandaron un posicionamiento moral expreso de condena por parte de los profesionales que, a veces, parecen tratar el problema con indiferencia y como si se tratase de una noticia cualquiera.

Con respecto a la segunda pregunta de investigación relativa a las percepciones sobre los posibles cambios en el tratamiento informativo a raíz de la promulgación de la Ley 1/2004 parecieron existir pequeñas diferencias que se determinaron insustanciales ya que, en definitiva, todas las participantes observaron un aumento de las informaciones pero no una mejoría en el tratamiento o en la calidad de las noticias en cuestión.

A la pregunta sobre cuáles eran sus reflexiones éticas sobre la actualidad y deber ser de la información periodística sobre VVCMM, las participantes concluyeron que los medios son agresivos en su tratamiento de la VVCCMM, de modo que reproducen o refuerzan la violencia. Así mismo, se consideró que la información era tratada como si fuera cualquier otra información. Por otra parte, que los medios son superficiales a la hora de narrar las violencias, transmitiendo una visión de incomprensión o desconocimiento. Por ejemplo, esto se manifiesta muy claramente cuando limitan la violencia a la física y obvian o ignoran la psicológica o simbólica, mucho más arraigada en la sociedad y siempre presente en la física. En esta misma línea, las participantes denunciaron que los relatos representados son sensacionalistas y se encuentran muy estereotipados. Finalmente, las mujeres comentaron que en las informaciones se culpabiliza a menudo a las mujeres explícita o implícitamente, transmitiendo la sensación de que las mujeres se merecen, se buscan o permiten la violencia gustosamente.

Entre las demandas de las mujeres se encuentran tres de gran relevancia aceptadas por todas las participantes: primero, la necesidad de tratar las VVCMM con mayor sensibilidad y habiendo realizado un trabajo de documentación previo más extenso y profundo; segundo, otorgar mayor relevancia al tema dándole más espacio y cobertura y tercero, representar todos los tipos de violencias existentes sin limitarse solo a la física, ofreciendo un discurso más rico, más completo y más real de la experiencia de la VVCMM.

En definitiva, este trabajo pone en evidencia la riqueza de las lecturas de las mujeres en contextos comunicativos centrados en las violencias y profundiza en la necesidad de avanzar en este tipo de estudios cualitativos, intensivos y "generizados". Entre los posibles retos de futuro está, pues, integrar un enfoque de género en los estudios sobre recepción y, en concreto, abrir vías de investigación que conduzcan a indagar en las lecturas y procesos de decodificación de los mensajes sobre VVCMM como basamento empírico sobre el que sustentar las numerosas guías y decálogos periodísticos.

\section{Referencias bibliográficas}

ALAT, Zeynep. News coverage of violence against women. The Turkish case. Feminist Media Studies, 6(3), 2006, pp.295-314.

ANDERSON, D. K. y SAUNDERS, D. G. Leaving an Abusive Partner: An Empirical Review of Predictors, the Process of Leaving, and Psychological Well-Being. Trauma, Violence, \& Abuse, (4), 2003, pp.163-191.

\footnotetext{
5 "Empirical evidence from studies that seek to understand the content of media messages has consistently demonstrated discrepancies between the realities of women's experiences of violence and the "reality" portrayed in the media and suggest that not much by way of positive change has occurred" (Shuterland et al., 2015:14).
} 
BADURA, Albert. Teoría social cognitiva de la comunicación de masas. In: BRYANT, Jennings y ZILLMANN, Dolf (comp.). Los efectos de los medios de comunicación. Investigaciones y teorías. Barcelona, Paidós, 1996, pp.88-126.

BARON, Robert; BYRNE, Don. Social psychology. Understanding human interaction. Boston, Allyn and Bacon, 1994.

BERKOWITZ, Leonard. Some effects and thoughts on anti-and prosocial influences on media events: a cognitive-neoassociation analysis. Psychological Bulletin, 95 (3), 1984, pp.410-427.

COYLE, Imelda. Sampling in qualitative research: purposeful and theoretical sampling; merging or clear boundaries? Journal of Advanced Nursing (26), 1997, pp.623-630.

DE MIGUEL, Ana. La construcción de un marco feminista de interpretación: la violencia de género. Cuadernos de Trabajo Social, 18, 2005, pp.231-248.

FESHBACH, Seymour. The catharsis hypothesis, aggressive drive and the reduction of aggression. Aggressive behavior (10), 1984, pp.91-101.

FULU, Emma et alli. Why Do Some Men Use Violence Against Women And How Can We Prevent It. Bangkok, Tailandia, UNDP, UNFPA, UN Women, UN Volunteers, 2013.

GANITO, Carla y FERREIRA, Cátia. Women and digital Reading: the gendering of digital Reading practices. In: CERQUEIRA, Carla; CABECINHAS, Rosa; MAGALHAES, Isabel (ed.). Gender in focus: (News) trends in Media. Braga, CECS-Centro de Estudos de Comunicação e Sociedade Universidade do Minho, 2016, pp.205-232.

GLASER, Barney. Grounded Theory 1984-1994. Mill Valley, ca, Sociology Press, 1995.

Basics of Grounded Theory Analysis. Emerge vs Forcing, Mill Valley, 1992.

Doing Grounded Theory. Mill Valley, Ca, Sociology Press, 1978.

HARRIS, Richard. A cognitive psychology of mass communication. Mahnaw, N.J., Lauwrence Erlbaum Associates, 1999.

HEILMAN, Brian; HEBERT, Luciana; PAUL-GERA, Natasia. The Making of Sexual Violence: How Does a Boy Grow Up to Commit Rape? Evidence from Five IMAGES Countries. Washington, EEUU, International Center for Research on Women (ICRW), Instituto Promundo, 2014.

MARTÍN-BARBERO, Jesús. Matrices culturales de la telenovela. Estudios sobre las culturas contemporáneas 2(005), 1998, pp.45-69.

MARTÍN-BARBERO, Jesús. Televisión y melodrama. Géneros y lecturas de la televisión en Colombia, 1992 [http://infohumanidades.com/sites/default/files/apuntes/25\%20-

\%20martin\%20barbero\%20Television\%20y\%20melodrama.pdf [acceso el 28/10/2021 ]

MARTÍN-BARBERO, Jesús. La telenovela en Colombia: televisión, melodrama y vida cotidiana. Signo y pensamiento (11), 1987, sp.

MILLER, David. Review of Women viewing violence. Critical Social Policy (40), 1994, pp.97-101.

PHILLIPS, David. The found experiment: a new technique for assessing the impact of mass media violence on real-world aggressive behavior. In: COMSTOCK, George (ed.). Public Communication and Behavior, v. I, Orlando, F.L., Academic Press, 1986, pp.260-308.

PUJADAS, Juan. José. El método biográfico. El uso de las historias de vida en ciencias sociales. Madrid, Centro de Investigaciones Sociológicas, 1992.

RADWAY, Janice A. Reading the Romance: Women, Patriarchy, and Popular Literature. Chapel Hill, NC, The University of North Caroline Press, 1991.

SANMARTíN, José et alii. III Informe Internacional. Violencia contra la mujer en las relaciones de pareja (estadísticas y legislación). Serie Documentos v.16, Valencia, España, Centro Reina Sofía, 2010.

SCHLESINGER, Philip et alii. Kay Women Viewing Violence. Londres, RU, BFI, 1992.

SORIANO, Jaume. Las mujeres ante la información de violencia de género. Sphera Pública (4), 2004, pp.51170. 
SUTHERLAND, Georgina et alii. Media guidelines for the responsible reporting of violence against women: a review of evidence and issues. Australian Journalism Review, 38(1), 2015.

SPARKS, Glen; SPARKS, Cherry W. Violence, mayhem and horror. In: ZILLEMAN, Dolf y VORDERER, Peter (ed.). Media entertainment. The psychology of its appeal. Mahwah, NJ, Lawrence Earlbaum Associates, 2000, 73-91.

STRAUSS, Ansel. Mirrors and Masks. Nueva York, NY, Free Press, 1959.

STRAUSS, Ansel; CORBIN, Juliet. Basics of Qualitative Research: Grounded Theory, Procedures and Techniques, London Sage, 1990.

VIVES-CASES, Carmen; TORRUBIANO, J.; ÁLVAREZ-DARDET, Carlos. The effect of television news items on intimate partner violence murders. European Journal of Public Health, 19(6), 2009, pp.592-596. 